\title{
Analysis of Nutrition of Collard Green Grown in China
}

\author{
Renju Chen ${ }^{1}$, Pengfei Zhang ${ }^{1}$, Li LI' ${ }^{1}$, Jie Xiao', Zhengquan SU ${ }^{2,3}$ and Tiancun Xiao ${ }^{1,3 *}$
}

${ }^{1}$ Guangzhou Boxabio Ltd, Guangzhou Hi-Tech Development Zone, PR China

${ }^{2}$ School of Public Health, Guangdong Pharmaceutical University, Guangzhou, PR China

${ }^{3}$ Inorganic Chemistry Laboratory, Oxford University, South Parks Road, OX1 3QR, UK

\begin{abstract}
Collard green is considered as one of the world healthiest vegetables. However, it has not been grown in China until recently. In these years, we have introduced the Collard Green seed in to China and grown in the foot the Qingling Mountain Area. The Vegetable grows well and can harvest twice a year in China. The green leaves have been processed under various conditions and dried to give fine powders. The nutrient elements in the various vegetable powders grown in China has been analysed and it is shown that the vegetable is slightly alkaline in its raw slurry. It is rich in $\mathrm{K}$ and $\mathrm{Zn}$, while very low in Na. The boiling cook leads to loss of nutrients such as nitrogen, $\mathrm{K}, \mathrm{Ca}$, and $\mathrm{Zn}$, while the raw washed and directly dried sample kept the most nutrient. The heavy metal content such as $\mathrm{Hg}$ and $\mathrm{As}$ and $\mathrm{Pb}$ are very low in the vegetable, probably due to the growth in the mountain uncontaminated area. In terms of the dry power yields ( $<6 \mathrm{wt} \%$ of moisture), roughly $10-13 \mathrm{Kg}$ of the as-harvested vegetable can give $1 \mathrm{~kg}$ of the vegetable powder.
\end{abstract}

Keywords: Collard green; Grown in china; Cooking drying; N content; Mineral analysis

\section{Introduction}

\section{Collard green}

Is the name for various loose-leafed cultivars of Brassica oleracea, part of the Acephala Group which also contains cabbage and broccoli. They are grown with their large, dark-colour, edible leaves as vegetables that are members of the cabbage family, but are also close relatives to kale [1-4]. Collard green has been widely grown in North American and Europe for more than hundred years. It cultivation dates back to prehistoric times, and is one of the oldest members of the cabbage family. The ancient Greeks grew kale and collards, although they made no distinction between them. Well before the Christian era, the Romans grew several kinds including those with large leaves and stalks and a mild flavor; broad-leaved forms like collards; and others with curled leaves (http://aggie- horticulture.tamu.edu/archives/parsons/ publications/ vegetabletravelers/kale.html).

In Europe and USA, collard greens are available year-round, but it may taste better when harvested in early spring or after Frost, which is less bitter, and it has been extensively used in the people meal in the region [5]. However, this kind of vegetable has not been grown in China, maybe due to it is rough texture and the bitter taste, no study on its nutrients have been reported from the China produce. It is known that the soil and the climate and the growing conditions have significant effect on the nutrients of the vegetables [6,7]. Hence in this work, we have grown the collard green in Northwest Part of China and processed the vegetables under different conditions to give dry vegetable powder. The composition of the different collard green samples has been studied in order to document macronutrient, micronutrient and non-nutrient composition and to provide new insights into the China produce collard green, which can be useful for modern diet and nutrition.

\section{Methods and Experimental Setup}

\section{Growing the collard green in China}

The experimental design was factorial based on randomized complete block design with three replications. Experimental factors included processing conditions. The collard green seed was sown on $6 \mathrm{~m} \times 9 \mathrm{~m}$ field divided into 3 plots Sowing depth was $1-1.5 \mathrm{~cm}$ and the seeds were placed into with $30-40 \mathrm{~cm}$ space. Soil moisture was kept at adequate levels to prevent water deficit and wilting. Weeds were controlled by hand as required. After 60 days of complete emergence of experimental field, samplings were done between lines regarding to marginal effects.

The collard green vegetable seed was bought from an UK vegetable seed supplier. The land is in the north side of Qingling Mountain, Tangyu Town, Mei County, Shaanxi Province, and North-western China, as shown in the map in Figure 1. The reasons for choosing this region are that it is not so hot and the soil is not contaminated, as there has been no pollution industry nearby. The $\mathrm{pH}$ of the soil is 6.7 , and the seed was sown at the middle of August, 2011. The sprout came out in 10 days and the $1^{\text {st }}$ harvest was carried out by collecting the underneath leaves in 60 days.

\section{Sampling}

Sampling was carried out from each plot $(3 \mathrm{~m} \times 3 \mathrm{~m})$ and mixed randomly and about $20 \mathrm{~kg}$ of the fresh vegetable samples were transferred to the laboratory. Before any measurements, the decay and withered tissues in the vegetable were removed and the edible parts were washed with tap water to remove surface dirt. The edible parts of vegetables were repeatedly rinsed with deionized water. Then the water in the leaves was dried by contacting the tissue paper to remove the dew to get fully drained vegetables.

*Corresponding author: Tiancun Xiao, Inorganic Chemistry Laboratory, Oxford University, South Parks Road, OX1 3QR, UK, Tel: 44-(0)1865-272; E mail: xiao.tiancun@chem.ox.ac.uk

Received January 25, 2014; Accepted March 01, 2014; Published March 19 2014

Citation: Chen R, Zhang P, Li LI, Xiao J, Zhengquan SU, et al. (2014) Analysis of Nutrition of Collard Green Grown in China. J Food Process Technol 5: 306. doi:10.4172/2157-7110.1000306

Copyright: (C) 2014 Xiao T, et al. This is an open-access article distributed unde the terms of the Creative Commons Attribution License, which permits unrestricted use, distribution, and reproduction in any medium, provided the original author and source are credited. 


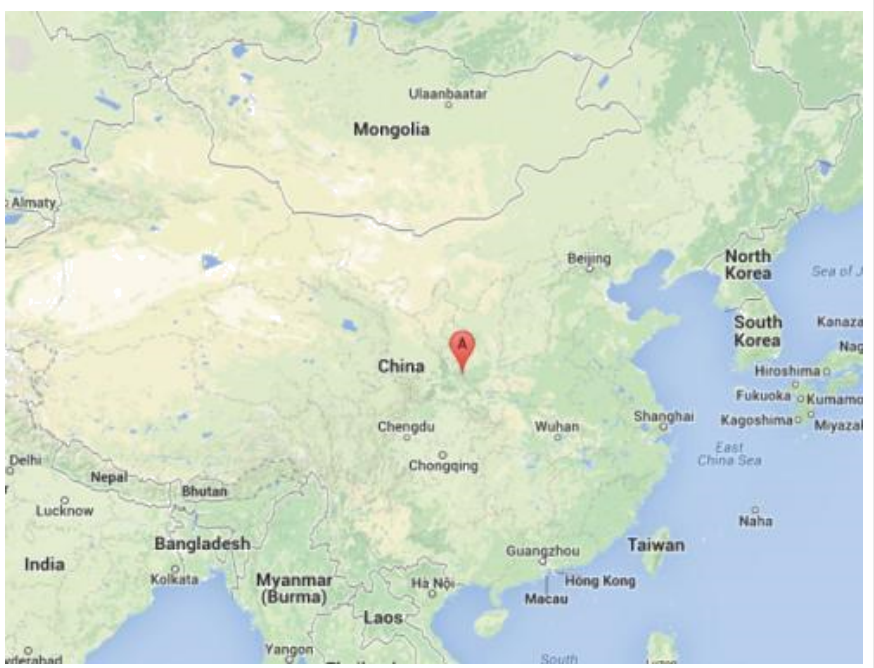

Figure 1: The map of the land where the collard green was introduced to China and grown.

\section{Sample treatment}

A specific amount of the drained vegetable was chopped to 2 inches and naturally dried for 1 hour in open air. Then about 500-700 g of chopped leaves was dried in an open at $70^{\circ} \mathrm{C}$ in static air until a constant weight is reached. Another portion (roughly 650g) of the chosen leaves was steamed cooked at $100^{\circ} \mathrm{C}$ for 2 hours, then open the pot and take the steamed leaves to open air and naturally dried for 30 minutes, weigh the mass. Yet another portion of the chopped and dried leaves was put into the 2 litre boiling water and boiled for 30 minutes, then filtered the water our and drained the leaved and open it and dried for 2 hours at room temperature until not attached dew seen in the leaves, then weigh it.

After weighing the sample, it was placed in a $70^{\circ} \mathrm{C}$ oven in static air to dry and weigh the amount every 2 hours. Until the weight was constant, the dried sample was then grounded into fine powder and sieved to 100-200 mesh. The resultant powder samples were vacuum packed and maintained at $2^{\circ} \mathrm{C}$ until analysis.

\section{Chemical analysis of the drained vegetable samples}

The nutrients in the fresh vegetable samples such as, protein, sugar, fat and crude fiber were analyzed. The total carbohydrate content was determined using difference method, protein content is calculated according to the Micro-kjeldhal method using a conversion factor of 6.25, fat measurement is through Soxhlet extraction method using petroleum ether (B.P. $55-70^{\circ} \mathrm{C}$ ), sugar and fibre were measured according to the AOAC method [8].

\section{Analysis of the vegetable powder samples}

The ash content of the sample was analyzed according to GB5413212010. Normally about 1 gram of the powder sample were calcined at $550^{\circ} \mathrm{C}$ (FP-300 series, Guangzhou Kepeng, $\pm 1.5^{\circ} \mathrm{C}$ at $1150^{\circ} \mathrm{C}$ ) for 2 hours until no smoke is seen, then weigh the residue.

The heavy metal contents, e.g., $\mathrm{Hg}, \mathrm{Pb}$ and $\mathrm{As}$ in the vegetable powder samples were determined using atomic fluorescence morphological analyzer (AFS-8230, Titan, Beijing, China). The amount of $0.612 \mathrm{~g}$ of each vegetable powder was digested in a mixture of $\mathrm{HNO}_{3}-$ $\mathrm{HClO}_{4}-\mathrm{H}_{2} \mathrm{O}_{2}(87: 13: 10=v / v / v)$. The $\mathrm{Hg}, \mathrm{Pb}$ and As concentrations of digestion solutions were determined. The detection limit should be as $\mathrm{Pb}$ is $<0.01 \mathrm{ug} / \mathrm{L}$ and for $\mathrm{Hg}$ is $0.001 \mathrm{ug} / \mathrm{L}$, the Relative Standard Deviation (RSD) is less than $1 \%$ for the same sample analysis.

CHNS analysis was carried out using the Carlo-Erba EA 1108 with PC based data system, Eager 200 for Windows and a Sartorious Ultra Micro Balance, 4504MP8. The macro and micro mineral element analysis was carried out according to GB.5413.21-2010, 5.0041 gram of the dried powder sample was taken and placed into a crucible, and placed onto a open electric furnace heated until no smog is generated, and then the half-burnt samples were transferred to a Muffle Oven calcined at $490^{\circ} \mathrm{C}$ for 5 hours in static air, cooled down to room temperature and dropped $1 \mathrm{ml}$ of $40 \% \mathrm{HNO}_{3}$, dried it in an electric furnace in fume hood, and then transferred to a Muffle Oven and calcined at $490^{\circ} \mathrm{C}$ again. A white ash about 0.5 grams was obtained. Then $10 \mathrm{ml}$ of $30 \% \mathrm{HCl}$ acid was added to the white ash and heated to about $60^{\circ} \mathrm{C}$ to dissolve the ash completely. The solution is transferred to a $50 \mathrm{ml}$ flask and top up water to $50 \mathrm{ml}$. The $\mathrm{Ca}, \mathrm{Na}, \mathrm{K}, \mathrm{Ca}, \mathrm{Mg}$ and the micro-element $\mathrm{Fe}, \mathrm{Mn}, \mathrm{Zn}$ and $\mathrm{Cu}$ were analyzed with Hitachi Z-5000 polarized Zeeman Atomic absorption spectrophotometer. Each sample was analysed 3 times, and the final value is obtained through the mean value of the 3 measured results.

\section{Statistical analysis}

The obtained data were tabulated and subjected to statistical analysis and mean separation was done using the least significant differences (LSD) test at $\mathrm{P}<0.05$ level of probability according to the method described by Snedecor and Cochran.

\section{Results and Discussion}

Collard Green was sown in the middle of August 2011 and it germinated in 10 days. The location of photo of the vegetable at different stages is shown in Figure 2. There have been 5-6 leaves when the seed was planted in 1 month, and the leaves were collected of the underneath with the collard grown high. There were some slugs and snail, which bite the leaves, and because no pesticide was used, the leaves had some holes. It is estimated from the harvest that the productivity of the collard green is up to $3000 \mathrm{~kg}$ per $667 \mathrm{M}^{2}$, (e.g., Mu in Chinese Area unit). It survives very well in winter when the frost comes.

In general, collard green grows well under the climate conditions at the foot of Qinling Mountain, and there are not so many insects attacked, except snail and slug. It was regularly watered and fertilized with cow manure.

The $\mathrm{pH}$ of the slurry was measured using an accurate $\mathrm{pH}$ paper, and the value was read at 6.25 , which suggests that the $\mathrm{pH}$ of the slurry

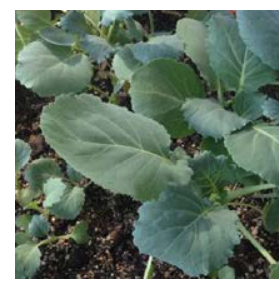

A

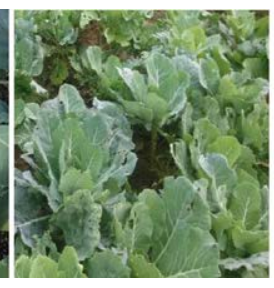

$\mathrm{b}$

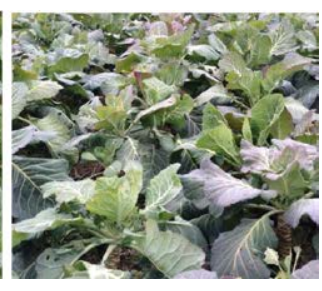

c
Figure 2: The photos of the Collard green grown in Shaanxi Province China at different stages a: 1 month after sowing, b: 2.5 months after sowing, c: 4.5 months after sowing in winter and frost. 
is almost neutral, very close to the vegetable grown in Spain and South Korea $[9,10]$.

The water content of the Collard Green grown in China was studied after it is treated with different methods. When it was just washed and then directly dried at $70^{\circ} \mathrm{C}$, the mass changes from 650.1 to $43.28 \mathrm{~g}$, the moisture content is about $93.5 \mathrm{wt} \%$. When the leaves is first boiled and drained with tissue paper and then dried, $628.4 \mathrm{~g}$ of the boiled vegetable gave about $49.62 \mathrm{~g}$ of dried mass. This suggested that the boiling in fact may take some water away from the fresh vegetable. When the fresh leaves were steamed, the moisture content was further decreased to $91.3 \%$, suggesting that steam treatment can remove more moisture from the fresh than the boiling (Table 1).

\section{The main component analysis of the differently treated collard green before drying}

The undried vegetable samples were analyzed for its contents of carbohydrate, sugar, dairy fibre, fat and protein, the results are shown in Table 2. In 100gram of the washed and drained sample, carbohydrate content is $7.83 \mathrm{~g}$, sugar is $0.62 \mathrm{~g}$, and dairy fibre is $2.94 \mathrm{~g}$, fat $0.46 \mathrm{~g}$ and protein $3.04 \mathrm{~g}$. When the sample was boiled, its contents of carbohydrate, sugar and protein decreased to some extent, while the fat and dairy fibre increased by more than $10 \%$, suggesting the boiling treatment, decreases leads to the loss of sugar and carbohydrate. The chopped and steamed process treatment of the vegetable sample did not change the contents of the main components of the sample, as the contents of carbohydrate, sugar; diary fibre and protein were almost the same as those in the washed and drained sample. There was slightly increase of fat content after steaming, to $0.51 \mathrm{~g} / 100 \mathrm{~g}$, this is still a very small difference. Generally speaking, the steaming treatment did not change the compositions of the main components significantly.

\section{The analysis of heavy metal in the resultant vegetable powder}

Vegetables often enrich some metal from the soils when it is grown under different environments. To test the safety of the vegetable powder, the heavy metal content in the collard green powders grown in China were analysed according to the GB5432-21-2010, and the $\mathrm{Hg}$ , $\mathrm{Pb}$, and As contents in the dry powder are shown in Table 3. It is shown that the $\mathrm{Hg}$ content is about $0.24 \mathrm{ug} / \mathrm{kg}$, in the rinsed and dried sample and almost no changes in the boiled or steam sample. These $\mathrm{Hg}$ contents are much less than the Chinese Government Indicators of Maximum Levels of Mercury in Foods (G/SPS/N/CHN/312) $\mathrm{Pb}$ content in the directly dried vegetable powder is about $0.071 \mathrm{mg} / \mathrm{kg}$, and $0.081 \mathrm{mg} / \mathrm{Kg}$ in the steamed and then dried sample, but slightly decreased in the steamed sample. $\mathrm{Pb}$ contents in all the China grown Collard Green powders are low in the vegetable powder, within the National Food safety limit $(0.3 \mathrm{mg} / \mathrm{Kg}$, G/SPS/N/CHN/312.). It is a bit difficult to understand $\mathrm{Pb}$ content is slightly high in the water boiled sample, which may be due to the loss of the soluble fibre and other soluble matters, and the insoluble $\mathrm{Pb}$ is relatively concentrated in the boiled sample. In the steamed vegetable powder, $\mathrm{Pb}$ content is slightly

\begin{tabular}{|c|c|c|c|}
\hline Sample & Initial weight (g) & Dry wt. (g) & Water content (\%) \\
\hline Rinsed and dried & $650.1 \pm 1.5$ & $43.28 \pm 0.32$ & $93.5 \pm 0.83$ \\
\hline Water boiled, then drained & $628.4 \pm 1.4$ & $49.62 \pm 0.35$ & $92.1 \pm 0.71$ \\
\hline Steamed and then dried & $581.8 \pm 1.5$ & $50.4 \pm 0.41$ & $91.3 \pm 0.79$ \\
\hline
\end{tabular}

The numbers in the table are the mean values the 3-time measurements Values with different subscripts are significantly difference at $p<0.05$

Table 1: Weight and moisture content of differently processed collard green grown in China. lower than the freshly dried sample but the difference is too small to be determined if it is from the analysis error or the real content.

As content in the differently processed collard green sample is lower than $\mathrm{Pb}$, ranging from $0.058 \mathrm{mg} / \mathrm{Kg}$ to $0.036 \mathrm{mg} / \mathrm{Kg}$ (in the boiled and drained sample). This suggests that some As may be soluble or minor soluble, as it has loss during the boiling process. The arsenic (As) content in the sample is also lower than the national food heavy metal limit $(0.5 \mathrm{mg} / \mathrm{kg}, \mathrm{G} / \mathrm{SPS} / \mathrm{N} / \mathrm{CHN} / 312$.$) .$

Based on the above analysis, it is concluded that the heavy metals of $\mathrm{Hg}, \mathrm{Pb}$ and $\mathrm{As}$ are within the national limit, which suggests that the vegetable grown in the region of China is safe. This can be explained that the land at the foot of Qinling (Tangyu Town) Shaanxi Province has no heavy industry before, and the land has never been contaminated.

\section{The CHNS analysis of the collard green grown in China}

The composition of the collard green grown in China was analysed using CHNS to determine the protein and organic sulphur and the results are shown in Table 4 . The naturally washed and dried sample has the highest $\mathrm{N}$ and $\mathrm{S}$ content, while its hydrogen and carbon contents are relativlely low. The nitrogen in vegetable is normally present in the form of protein. According to the literature, the overall protein concentration is calculated according Kjeldahl method [11-13], which is the content of nitrogen times by 6.25 . Therefore the total protein content in the directly dried sample is $25.2 \mathrm{wt} \%$. This may be lower than the protein content in the fresh vegetable, as it has been reported that the fresh $100 \mathrm{~g}$ of the collard green contain $1.5-4.5 \mathrm{~g}$ protein $[3,4]$, and more than 1000 gram of the fresh can give less than 100 gram of the powder. This suggests that the collard green grown in Shaanxi China has the reasonable protein content, which yet may get lost during the drying process.

The $1.03 \mathrm{wt} \%$ sulfur in collard green is probably part isothiocyanate, especially sulforaphane, which is rich in crucifer vegetables, and it is a molecule within the group of organosulfur compounds of isothiothene. This has been considered as an active compound to be potentially effective at inhibiting Helicobacter pylori growth. Therefore it is inferred that that the resulted powder may be a good agent for stomach bacteria relieve and possessing anti-cancer effect [14-16].

When the leaves are firstly boiled and then dried to give the vegetable powder, the carbon and hydrogen contents increase to about $39.44 \%$, and $6.22 \mathrm{wt} \%$ respectively, the $\mathrm{H} / \mathrm{C}$ atomic ratio is 1.89 , which is less than the typical carbon hydrate $-\left(\mathrm{CH}_{2} \mathrm{O}\right)-n$, as there is significantly amount of protein and sulforaphane in the vegetable powder. Nitrogen content decreases to $3.59 \mathrm{wt} \%$ and sulfur to $0.65 \mathrm{wt} \%$. This suggests that the boiling process leads to some loss of protein and isothiocyanate. This part of protein may be some soluble and has gone with the boiling water. There may be some mineral loss as well, as the yield of dried mass is less.

When the fresh leaves were washed and steamed, then dried and converted into vegetable powder, the $\mathrm{C}$ and $\mathrm{H}$ contents become higher than the freshly dried sample, but less than the boiled sample. However, the $\mathrm{N}$ and $\mathrm{S}$ contents are also less than the fresh dried sample, which may be due to the condensed steam leachate of the leaves in the steaming process.

\section{The analysis of macro and micro mineral elements of the vegetable powders}

The mineral elements in the variously processed collard green 


\begin{tabular}{|c|c|c|c|c|}
\hline Collard green & Carbohydrate & Sugar g/100g & Dairy fibre & Fat g/100g \\
\hline Sample Treatment & $\mathbf{g} / \mathbf{1 0 0 g}$ & & $\mathbf{g} / \mathbf{1 0 0 g}$ & $\mathbf{g} / \mathbf{1 0 0 g}$ \\
\hline Washed, Drained and Chopped & $7.83 \pm 0.53$ & $0.62 \pm 0.011$ & $2.94 \pm 0.063$ & $0.46 \pm 0.003$ \\
\hline Chopped, Boiled and Drained & $7.21 \pm 0.49$ & $0.56 \pm 0.018$ & $3.22 \pm 0.056$ & $0.56 \pm 0.004$ \\
\hline Chopped and Steamed & $7.85 \pm 0.55$ & $0.63 \pm 0.015$ & $2.97 \pm 0.072$ & $0.51 \pm 0.004$ \\
\hline
\end{tabular}

The numbers in the table are the mean values the 3-time measurements of each sample

Values with different subscripts are significant difference at $p<0.05$

Table 2: The main components of the differently treated Collard Green grown in China before drying treatment.

\begin{tabular}{|c|c|c|c|c|}
\hline Differently Processed & Sample number & Hg (mg/kg) & Pb $(\mathbf{m g} / \mathbf{k g})$ & $0.071 \pm 0.062$ \\
\hline Rinsed and dried & 5 & $0.00024 \pm 0.00022$ & $0.058 \pm 0071$ \\
\hline Steamed then dried & 4 & $0.00025 \pm 0.00019$ & $0.081 \pm 0.072$ \\
\hline Boiled, drained and dried & 6 & $0.00021 \pm 0.00021$ & $0.053 \pm 0.067$ \\
\hline
\end{tabular}

These are 3-time mean values of the measured experimental results Values with different subscripts are significantly difference at $p<0.05$

Table 3: the Heavy metal contents in the different processed collard green grown in China.

\begin{tabular}{|c|c|c|c|}
\hline Sample & $\mathbf{C}(\mathbf{w t} \%)$ & $\mathbf{H}(\mathbf{w t} \%)$ & $\mathbf{N}(\mathbf{w t} \%)$ \\
\hline Hot air dried & $34.33 \pm 0.12$ & $4.48 \pm 0.05$ & $4.43 \pm 0.035$ \\
\hline Boiled & $39.44 \pm 0.14$ & $6.22 \pm 0.065$ & $3.59 \pm 0.041$ \\
\hline Steamed & $36.62 \pm 0.13$ & $5.36 \pm 0.0054$ & $0.65 \pm 0.032$ \\
\hline
\end{tabular}

Table 4: CHNS analysis of the dried sample from differently processed collard Green in China.

\begin{tabular}{|c|c|c|c|c|c|}
\hline $\mathbf{m g} / \mathbf{1 0 0 g}$ dry powder & Ash Content $\mathbf{( m g / g )}$ & $\mathbf{N a}$ & $\mathbf{K}$ & $\mathbf{C a}$ \\
\hline Washed and Dried & $136.82 \pm 3.16$ & $437.41 \pm 19.56$ & $2788.21+28.76$ & $1568.92 \pm 19.91$ \\
\hline Boiled Cooked & $122.91 \pm 2.96$ & $396.6 \pm 12.29$ & $962.18 \pm 30.68$ & $1242.32 \pm 18.69$ \\
\hline Steamed & $146.62 \pm 3.22$ & $426.8 \pm 16.53$ & $2326.23 \pm 29.81$ & $1665.1 \pm 21.28$ \\
\hline
\end{tabular}

The numbers in the table are the mean values the 3 measurements of each sample

Values with different subscripts are significant difference at $p<0.05$

Table 5: The ash content and the macro-elements in the collard green grown in China.

\begin{tabular}{|c|c|c|c|c|}
\hline Micro element $\mathbf{m g} / \mathbf{1 0 0 g}$ dry powder & Fe & Mn & Zn \\
\hline washed and dried & $19.62 \pm 0.621$ & $8.241 \pm 0.535$ & $3.265 \pm 0.512$ \\
\hline boiled cooked & $17.12 \pm 0.479$ & $6.832 \pm 0.215$ & $2.956 \pm 0.109$ \\
\hline steamed & $20.36 \pm 0.293$ & $7.926 \pm 0.369$ & $0.0821 \pm 0.00868$ & $3.36 \pm 0.212$ \\
\hline
\end{tabular}

The numbers in the table are the mean values the 3 measurements

Values with different subscripts are significant difference at $p<0.05$

Table 6: The micro-elements in the differently processed collard green grown in China.

grown in China have been analyzed and the results are shown in Table 5. The ash content in the rinsed and dried sample is about $13.6 \%$, suggesting it has relatively high mineral content, in agreement with the vegetable grown elsewhere [17]. When it was boiling cooked, the ash content was decreased to $12.3 \%$. The steamed collard green powder has ash content of $14.6 \%$, which may be due to the loss of the volatile organic compounds during the steam treatment. The sodium content in the washed and dried sample is more or less the same as the steamed sample. When the collard green is boiled, there is some loss of sodium, which is about $0.4 \mathrm{wt} \%$ in the dried powder, as sodium compounds are mostly soluble in water. The washed and rinsed vegetable powder has the highest $\mathrm{K}$ content, up to $2.7 \mathrm{wt} \%$, which could be a very good source for the $\mathrm{K}$ intake for some special people in need. Compared to the collard green grown outside of China, the $\mathrm{K}$ content in the vegetable grown in Shaanxi China is fairly high, much higher than the one grown in Bangladesh [18], and equivalent to the one grown in Europe or US $[3,9,19]$. However, the boiling treatment leads to the $\mathrm{K}$ decrease to $0.96 \mathrm{wt} \%$ in the vegetable powder, more than half of $\mathrm{K}$ is leached to the water, forming the potassium rich soup. The boiling treatment on the vegetable also results in the loss of $\mathrm{Ca}$ and $\mathrm{Mg}$, however, their content are all above $1.2 \mathrm{wt} \%$, and the highest occurs in the steam, which is about $1.66 \mathrm{wt} \%$. This shows that the collard green grown in China is also a good source of Ca supplement, and the boiling treatment has less effect on the $\mathrm{Ca}$ leachate from the vegetable. The Mg content is lower than $\mathrm{Ca}$, and its content in the differently treated vegetable powder samples is from $0.21 \mathrm{wt} \%$ to $0.27 \mathrm{wt} \%$, which can also help for the supplement for $\mathrm{Mg}$

The micro mineral element contents in the powder of collard green grown in China are given in Table 6. It is seen that the washed and directly dried powder has about $19 \mathrm{mg}$ of Fe content, $8.34 \mathrm{mg}$ of $\mathrm{Mn}$, $3.3 \mathrm{mg}$ of $\mathrm{Zn}$ and $0.0821 \mathrm{mg}$ of $\mathrm{Cu}$ in 100 gram of the vegetable powder. When it is boiled in water and then dried, the resultant powder has less $\mathrm{Fe}, \mathrm{Mn}, \mathrm{Zn}$ and almost equivalent of $\mathrm{Cu}$, suggesting that there are some loss of $\mathrm{Fe}, \mathrm{Mn}$ and $\mathrm{Zn}$ during the water boiling process, which may be due to the solubility of the Fe and Mn containing phytochemicals in the collard green. When steamed and then dried, the Fe, Mn, $\mathrm{Zn}$ and $\mathrm{Cu}$ contents in the vegetable powder increase slightly compared to the directly dried sample, except $\mathrm{Mn}$ is slightly lower. This may be due to the steam treatment, which is $100^{\circ} \mathrm{C}$ and leads to some light volatile elements loss, the light element might be mainly from the organic, which is composed of $\mathrm{C}, \mathrm{H}, \mathrm{N}$ or sulphur. However, the heavy metal 
elements may not be reached. Therefore the micro-mineral elements are increased a little bit in the steamed and dried sample.

It should be noted that although there is a slightly trend in the micro-element increase, the results are still within the analysis error limit, therefore, it is not certain that the steam treatment does enrich the microelement.

Generally speaking, the above results showed that the fresh rinsed and directly dried sample preserves the maximum nutrients of the vegetables in the dried powder form.

\section{Conclusion}

Collard green has been considered as one of the healthiest vegetable, and was introduced to China and grown at the foot of Qinling Mountain, Shaanxi Province China. The vegetable grew well under the local climate conditions, and the fresh vegetable yield can be $3000 \mathrm{Kg}$ per $667 \mathrm{M}^{2}$ in one harvests. The vegetable juice has $\mathrm{pH}$ of 6.15 .

The vegetables have been processed under various conditions, and dried to give vegetable powders, which has a yield of 8-10\% depending on the process conditions. The analysis of the vegetable powders showed that the heavy metal contaminations are much low in all the powder samples, which may be due to the uncontaminated soil land.

The vegetable has high content of $4.43 \mathrm{wt} \%$ of $\mathrm{N}$ and $1.03 \mathrm{wt} \%$ of $\mathrm{S}$, equivalent of $25.2 \mathrm{wt} \%$ protein. The water boiling treatment results in some loss of protein and sulphur containing compounds and also the macro-mineral elements especially $\mathrm{K}$. Rinsing with water and directly drying process helps to reserve the maximum mineral elements.

To preserve the maximum nutrient of the collard green in the vegetable powder, the washing, drained and directly drying process would be preferred. This leads to little loss of the macro and micro mineral elements, also it is simpler and save energy.

\section{References}

1. Kahlon TS, Chiu MCM, Chapman MH (2008) Steam cooking significantly improves in vitro bile acid binding of collard greens, kale, mustard greens, broccoli, green bell pepper, and cabbage. Nutr Res (NY, US) 28: 351-357.

2. Kahlon TS, Milczarek RR, Chiu MCM (2012) In vitro bile acid binding of mustard greens, kale, broccoli, cabbage and green bell pepper improves with sauteing compared with raw or other methods of preparation. Food Nutr Sci 3: 951-958.

3. Miller-Cebert RL, Sistani NA, Cebert E (2009) Comparative mineral composition among canola cultivars and other cruciferous leafy greens. J Food Compos Anal 22: 112-116.

4. Mosha TC, Gaga HE (1999) Nutritive value and effect of blanching on the trypsin and chymotrypsin inhibitor activities of selected leafy vegetables. Plant Foods Hum Nutr 54: 271-283.

5. Tordoff, M.G. and M.A. Sandell (2009) Vegetable bitterness is related to calcium content. Appetite (Amsterdam Neth) 52: 498-504.

6. Menon MP (1993) Fly ash-amended compost as manure for agricultural crops J Environ Sci Health Part A A28: 2167-2182.

7. Noufal EHA (2004) Effect of irrigation water quality on germination growth and mineral content of barley grown on a sandy soil. Egypt. J Soil Sci 44: 215-226.

8. Casterline JL Jr, Oles CJ, Ku Y (1999) Measurement of sugars and starches in foods by a modification of the AOAC total dietary fiber method. J AOAC Int 82: 759-765.

9. Martinez S (2010) Protein, amino acid, ash and mineral contents in Brassica spp. grown in Northwest Spain. Int J Food Sci Technol 46: 146-153.

10. Kim SY (2012) Comparison of nutritional compositions and antioxidant activities of building blocks in shinseoncho and kale green vegetable juices. Prev Nutr Food Sci 17: 269-273.

11. Koehler HH, Hard MM (1983) Protein, fat, and amino acid content and protein quality of selected pre-prepared foods. J Am Diet Assoc 82: 241-245.

12. Levinson LR, Gilbride KA (2011) Detection of melamine and cyanuric acid in vegetable protein products used in food production. J Food Sci 76: C568-575.

13. Simonne AH (1997) Could the Dumas method replace the Kjeldahl digestion for nitrogen and crude protein determinations in foods. J Sci Food Agric 73: 39-45.

14. Sasaki K (2012) Quantitative profiling of glucosinolates by LC-MS analysis reveals several cultivars of cabbage and kale as promising sources of sulforaphane. J Chromatogr B Anal Technol Biomed Life Sci 903: 171-176.

15. Sivakumar G, Aliboni A, Bacchetta L (2007) HPLC screening of anti-cancer sulforaphane from important European Brassica species. Food Chem 104: 1761-1764.

16. Zareba G, Serradell N (2004) Chemoprotective effects of broccoli and other Brassica vegetables. Drugs Future 29: 1097-1104.

17. Hove EL (1977) High-protein food prepared from fresh leafy material by alcoho drying and mechanical defibring. J Agric Res 20: 309-313.

18. Abu BM, Islam S, Abdullah AM (2011) Studies of minerals in vegetables available at Chittagong City in Bangladesh. EJEAFChe, Electron. J Environ Agric Food Chem 10: 2365-2370.

19. Vigo C, Therios IN, Bosabalidis AM (2005) Plant growth, nutrient concentration, and leaf anatomy of olive plants irrigated with diluted seawater. J Plant Nutr 28: 1001-1021. 